\title{
Lending Booms, Sharp Reversals and Real Exchange Rate Dynamics
}

\section{Citation}

Gopinath, Gita. 2003. Lending booms, sharp reversals and real exchange rate dynamics. Journal of International Economics 62(1): 1-23.

\section{Published Version}

http://dx.doi.org/10.1016/j.jinteco.2003.08.002

\section{Permanent link}

http://nrs.harvard.edu/urn-3:HUL.InstRepos:11988005

\section{Terms of Use}

This article was downloaded from Harvard University's DASH repository, and is made available under the terms and conditions applicable to Other Posted Material, as set forth at http:// nrs.harvard.edu/urn-3:HUL.InstRepos:dash.current.terms-of-use\#LAA

\section{Share Your Story}

The Harvard community has made this article openly available.

Please share how this access benefits you. Submit a story.

\section{Accessibility}




\title{
Lending Booms, Sharp Reversals and Real Exchange Rate Dynamics
}

\author{
Gita Gopinath* \\ University of Chicago \\ Graduate School of Business
}

May 6, 2003

\begin{abstract}
Emerging market economies in the nineteen nineties have experienced periods of booms followed by collapses in gross domestic product, consumption, traded and nontraded sector output and real exchange rate movements alongside unprecedented movements in foreign investor participation in these economies. An important feature of these episodes is the asymmetry in the pattern of booms and collapses. We introduce a natural search friction into the foreign investment decision in a small open economy and demonstrate that this can generate both the gradual appreciations in the real exchange rate and growth in production during expansions and the asymmetrically sharp downward adjustment during contractions. The magnitude of the reversals predicted by the model can be quantitatively large and empirically relevant. The adjustment hazard model of investment we present generates predictions that differ qualitatively from the standard quadratic adjustment cost model of investment.
\end{abstract}

\footnotetext{
${ }^{*}$ I am especially thankful to Mark Aguiar, Ben Bernanke, Ariel Burstein, Steve Davis, Pierre-Olivier Gourinchas, Amartya Lahiri, Wojciech Olszewski, Assaf Razin, Kenneth Rogoff, Alwyn Young and two anonymous referees for their advice on this paper. I also wish to thank seminar participants at Cornell University, Delhi School of Economics, NBER International Finance summer meetings, Society of Economic Dynamics meetings, University of Washington, Wharton School of Business and University of Wisconsin for comments. All remaining errors are my own. email: gita.gopinath@gsb.uchicago.edu. Tel: (773)7029297.
} Fax: (773)7020458 


\section{Introduction}

Emerging market economies in the nineteen nineties have experienced periods of booms followed by collapses in gross domestic product, consumption, traded and non-traded sector output and real exchange rate movements alongside unprecedented movements in foreign investor participation in these economies. The empirical stylized facts of this phenomenon have been documented extensively in Calvo-Leiderman-Reinhart (1996), Calvo-Reinhart (1999) and Glick (1998). An important feature of these episodes is the asymmetry in the pattern of booms and collapses. Booms have been associated with gradual appreciations in the real exchange rate and growth in production and consumption. Collapses on the other hand have involved dramatic reversals with sharp contractions in GDP, relative price of non-traded goods, the real exchange rate and large exit of foreign investors from the crisis economy. This paper presents a theoretical framework to explain the boom and collapse episodes of emerging economies with specific emphasis on the asymmetry of the process. The model describes a micro-foundation based adjustment friction in foreign investor entry and exit into a small open economy. The predictions are shown to differ qualitatively from a framework where the friction is modeled as a quadratic adjustment cost in investment as is the case in the standard $q$ model of investment.

We describe a small open economy with return seeking foreign investment flows. The source of friction in these flows emerges from information imperfections about investment returns in the emerging markets. Investment 'projects' are characterized by idiosyncratic returns and the type of the project can be determined only through a time consuming search process. The decision to invest, accordingly, weighs the return from a current project against the outside option and the option value of further search. The endogenously determined entry and exit decision for the foreign investor generates dynamics in the path of net project creation that in turn generate the responses of real variables that has been observed in emerging market economies.

Our model is distinct from the earlier literature in that it incorporates the direct economic effects of a friction in foreign investor entry and exit decisions in a small open economy. Accordingly it generates the sharp reversals in foreign investor participation observed in 
these economies. The existing theoretical literature can be broadly divided into two strands of explanations. One set of explanations rely on the inter-temporal consumption smoothing mechanism to obtain dynamics in the real exchange rate. Several papers (Calvo-Vegh (1993)) that model exchange rate based stabilization programs that are imperfectly credible rely on this mechanism. Since the empirical evidence on intertemporal substitution is weak, Rebelo-Vegh (1995) who survey explanations based on exchange rate based stabilizations in high inflation economies conclude that it is "very difficult to explain the magnitude of the real appreciation and consumption booms" on the basis of these explanations. Moreover, these papers do not address the asymmetric adjustment that we observe. In more recent work, Calvo-Mendoza (2000) and Mendoza (2001) combine this mechanism with an 'occasionally binding' credit constraint to generate 'sudden stops' when fundamentals deteriorate. We describe a mechanism where symmetric shocks to fundamentals generate asymmetric responses even when the constraint (adjustment friction) is always effective. A second strand of the literature extends the Kiyotaki-Moore credit-cycle mechanism to generate dynamics in the real exchange rate. Aghion-Bacchetta-Banerjee (1999) generate equilibria with endogenous cycles in the relative price of non-traded goods and investment. Tornell-Schneider (2000) combine bailout guarantees with the credit cycle mechanism to generate self-fulfilling boom-bust phenomena. Both these papers however do not address the asymmetry of the adjustment process $^{1}$. In this paper we examine phenomena that are not limited to exchange rate based stabilization episodes and is therefore closer to the sudden stops analysis surveyed in Arellano-Mendoza (2002).

The application of search theory to investment is uncommon in the literature. However it seems natural to consider search frictions in foreign investment. The mechanism described has the following features. Foreign investors seeks high return investment projects in an emerging market. They invest in projects that engage in real activity in the emerging market and generate a stream of returns for the investor. Foreign Investors are constrained in their investment decisions by the need to determine the idiosyncratic type of the project

\footnotetext{
${ }^{1}$ Tornell-Schneider (2000) discuss a different asymmetry that relates to the difference in the post-crisis recovery dynamics between the traded and non-traded sector.
} 
through a time consuming evaluation process and face an endogenously determined adjustment hazard. The investor has an incentive to search for a project with high idiosyncratic returns and investment decisions will incorporate the option value to waiting. Domestic households benefit from the higher income earned from the projects. At any point in time we observe both so called 'project creation' when new projects get activated by foreign investors and 'project destruction' when foreign investors withdraw from projects. The prolonged appreciation in the real exchange rate and gradual expansion in GDP, traded sector output and measure of active projects, in response to an improvement in investment fundamentals is a consequence of the optimal decisions of investors to wait and seek good matches. On the other hand, in response to a deterioration in fundamentals, previously good matches now provide inadequate returns and one observes a sudden rise in project destruction that in turn generates the asymmetrically sharp contraction in GDP, traded sector output, measure of active projects and real exchange rate. In Section 3 we calibrate the parameters of the model and quantitatively evaluate the impact of shocks to traded sector productivity and fixed costs of investment. The impact effect and long-run effect of these shocks are contrasted between two scenarios: when the economy moves from a good state to a bad state and vice versa. The asymmetry in adjustment is quantitatively important. For instance, a $6.5 \%$ increase in traded sector productivity, when the economy moves permanently to the good state, is shown to raise GDP on impact by $1.69 \%$ and in the long-run by $5.15 \%$. In contrast, a drop in traded sector productivity as the economy moves to the bad state, is shown to generate a $7.17 \%$ drop in GDP on impact, with a long-run decline of $4.9 \%$. The magnitude of the reversals predicted by the model can be quite large and comparable to estimates obtained in the data.

The model of investment flows we present can be viewed as an 'adjustment hazard' model of investment flows across borders. It is therefore useful to compare it with the standard work-horse model of adjustment dynamics in investment-the quadratic adjustment cost $q$ model of investment. Our approach separates the gross flows underlying the net investment process and this separation makes important predictions for the adjustment path of net investment. Symmetric positive and negative shocks generate asymmetric responses in the adjustment path of net project creation. In the standard $q$ model the adjustment is 
symmetric $^{2}$.

The rest of the paper proceeds as follows. In Section 2, we describe the model. In Section 3 , we discuss the parameter values used to calibrate the model. Section 4 describes the steady state characteristics of the economy and Section 5 analyzes the dynamic adjustment response of the economy. Finally, we conclude in Section 6.

\section{The Model}

The model describes a small open-economy with two types of agents-the domestic household and the foreign investor. We describe the latter in Section 2.1 and the former in Section 2.2. There are two types of goods - a traded good ( traded good is treated as the numeraire. The price of the non-traded good in terms of the traded good is $p$.

\subsection{The Foreign Investor}

Investment opportunities in the small open-economy are described by 'projects' that are associated with domestic households. These projects produce traded goods using nontraded goods as inputs. The per period profit from a project is given by $\pi_{\mathrm{T}, \mathrm{t}}(\theta)$ where $\theta$ represents the idiosyncratic return from the project. Foreign participation is viewed as improving the efficiency of the projects. To simplify the analysis, we assume that $\pi_{\mathrm{T}, \mathrm{t}}(\theta)$ is strictly positive only when associated with a foreign agent ${ }^{3}$. Accordingly, in the absence of foreign participation, these projects become inactive. As long as the project remains active the foreign and domestic agent share profits according to a fraction $\tau$ and $(1-\tau)$ respectively.

\footnotetext{
${ }^{2}$ Caballero (1997) and Caballero-Engel (1998) have a series of papers on a more general $q$ model in which they assume asymmetric stochastic adjustment cost functions. Our model derives the stochastic adjustment process based on a specific friction in the investment process and is therefore micro-founded.

${ }^{3}$ This extreme assumption is not necessary for the qualitative results we derive. All we require is that there is some negative effect of the withdrawal of foreign investment on the real activity of the project.
} 
The production function for a type $\theta$ project in the traded sector is as below,

$$
y_{\mathrm{T}, t}(\theta)=\theta+z_{t} x_{\mathrm{N}, t}^{\alpha}
$$

$z$ is a measure of the aggregate level of productivity in the traded sector (and is deterministic). $x_{\mathrm{N}, t}$ is the quantity of non-traded goods used as inputs in production.

A risk neutral foreign investor is endowed with $\phi$ units of the traded good every period, which he must decide between investing or reinvesting in project $\theta$ or investing in the international capital market at the risk free world interest rate of $r$. First, consider a foreign investor who is invested in a type $\theta$ project. The idiosyncratic type of the project $\theta$ is assumed to stay constant over time. At the start of every period, the investor decides whether to reinvest in the project or exit the project. If he exits, he enters the pool of searchers in the following period and draws from a distribution of projects represented by $G(\theta) . G(\theta)$ is assumed to be unchanging over time. In addition, there is an exogenous probability of shut-down $\delta$ each period after the firm produces at time $t$, in which case once again the investor enters the pool of searchers in $t+1$. ( $\beta$ is the time discount rate $)^{4}$.

The asset value of a type $\theta$ project for a foreign investor, $R_{t}(\theta)$ is then

$$
R_{t}(\theta)=\tau \pi_{\mathrm{T}, t}(\theta)+\beta(1-\delta) V_{t+1}(\theta)+\beta E_{\theta} V_{t+1}(\theta)
$$

where

$$
V_{t}(\theta)=\max \left[R_{t}(\theta),(1+r) \phi+\beta E_{\theta} V_{t+1}(\theta)\right]
$$

$V_{t}(\theta)$ is the value to the investor of choosing optimally between investing in a project of type $\theta$ or not. The asset value $R_{t}(\theta)$ incorporates the possibility that the investor will choose to exit from the project in the future. An investor will be indifferent between exiting a project and reinvesting in a project as long as the value from exiting $(1+r) \phi+\beta E_{\theta} V_{t+1}(\theta)$ and from reinvesting $R_{t}(\theta)$ are equal. There is an optimal cut-off exit condition $\hat{\theta}_{t}$ such that foreign agents will exit all projects of type $\theta<\hat{\theta}_{t}$ and retain their investment in all types $\theta \geq \hat{\theta}_{t}$.

\footnotetext{
${ }^{4}$ The per-period cost of investment could have alternatively been denominated in terms of a bundle of traded and non-traded goods. This would not alter the main results.
} 
Next, consider an investor who is currently in the pool of searchers. The search assumption captures the idea that foreign investors are faced with heterogenous investment opportunities and in the absence of adequate information regarding the types of projects in emerging markets need to determine the type of a project through a time-consuming process. Accordingly, foreign investment is not frictionless. This assumption of information imperfections is finding empirical support in recent literature on the determinants of capital flows across borders (Ghosh-Wolf (1999), Portes-Rey (2000)) ${ }^{5}$. The importance of searching for investment projects is relevant for most capital flows where the investor when faced with several options invests time and money to determine the optimal investment. Since investors are allowed to exit the economy relatively quickly we do not restrict capital flows to long-term investments.

Every period a searching investor draws a project from the distribution $G(\theta)$ and determines its type. If they choose to invest $\phi$ in the asset they obtain $R_{t}(\theta)$ and if they choose to continue searching they obtain $(1+r) \phi+\beta E_{\theta} V_{t+1}(\theta)$. The decision rule for a searching investor is therefore identical to the one faced by the foreign investor who is attached to a project and has to decide between re-investing or exiting each period. Accordingly, we define $\hat{\theta}_{t}$ to be the cut-off level of idiosyncratic productivity such that a matched investor will be indifferent between staying with the project or exiting the project, and a searching investor will be indifferent between accepting the project and rejecting it to search again.

$$
\hat{\theta}_{t}=\inf \left\{\theta \in\left[\theta_{L}, \theta_{H}\right]: R_{t}(\theta) \geq(1+r) \phi+\beta E_{\theta} V_{t+1}(\theta)\right\}
$$

$\hat{\theta}_{t}$ is both the entry cut-off for the searching investor and the exit cut-off for the matched investor. The adjustment hazard for an individual investor is represented by $\left(1-G\left(\hat{\theta}_{t}\right)\right)$. That is, with a probability of $\left(1-G\left(\hat{\theta}_{t}\right)\right)$ the investor will expect to successfully invest. Since $\hat{\theta}_{t}$ is a forward looking variable the adjustment hazard term incorporates information about the expected future path of returns. Investors will reject projects that provide them with a return less than the world interest rate and will be more selective the higher the option value to waiting. As long as foreign investors limit the amount they are willing to

\footnotetext{
${ }^{5}$ Portes-Rey (2000) conclude from an empirical study that the geography of information is a crucial determinant of the pattern of international transactions.
} 
invest in an emerging market so that it isn't the case that all profitable projects in emerging markets get absorbed immediately the incentive to search will be high. The evidence on supply of capital to emerging markets suggests that capital flows across borders is limited for several reasons including the high level of political risk, adjustment costs, congestion effects and home-bias in preferences.

We assume that there is a fixed pool of foreign investors of measure one that seeks investment opportunities in the emerging economy. We define $\eta_{t}$ to be the measure of investors that are searching at the start of time $t . m_{t}(\theta)$ is the mass of investors with project $\theta$ at time $t$, after the entry and exit decisions but before exogenous exit (which takes place with probability $\delta) \cdot m_{t}(\theta)$ evolves as

$$
\begin{aligned}
m_{t}(\theta) & =(1-\delta) m_{t-1}(\theta)+\eta_{t} g(\theta) . & & \text { if } \theta \geq \hat{\theta}_{t} \\
& =0 & & \text { if } \theta<\hat{\theta}_{t}
\end{aligned}
$$

$m_{t}(\theta)$ includes all surviving active projects from period $t-1$ whose idiosyncratic return continues to be above the cut-off and new matches of type $\theta$.

The measure of searching investors includes all investors who continue searching from the previous period and all investors who endogenously and exogenously exit from their matches.

$$
\eta_{t}=\int_{\theta_{L}}^{\hat{\theta}_{t-1}} \eta_{t-1} d G(\theta)+(1-\delta) \int_{\theta_{L}}^{\hat{\theta}_{t-1}} m_{t-2}(\theta) d \theta+\delta m_{t-1}
$$

$m_{t}=\int_{\theta_{L}}^{\theta_{H}} m_{t}(\theta) d \theta$. Given that there is a fixed total pool of investment seekers of measure one, the relation between the measure of searching investors and active projects is given by

$$
\eta_{t}+(1-\delta) \int_{\theta_{L}}^{\theta_{H}} m_{t-1}(\theta) d \theta=1
$$

The evolution of the total measure of active projects is then

$$
m_{t}=m_{t-1}+\eta_{t}\left(1-G\left(\hat{\theta}_{t}\right)\right)-\left[(1-\delta) \int_{\theta_{L}}^{\hat{\theta}_{t}} m_{t-1}(\theta) d \theta+\delta m_{t-1}\right]
$$

The level of what we shall call project creation at any point of time is then, $C_{t}=\int_{\hat{\theta}_{t}}^{\theta_{H}} \eta_{t} d G(\theta)$ and the so-called level of project destruction is $D_{t}=\left[(1-\delta) \int_{\theta_{L}}^{\hat{\theta}_{t}} m_{t-1}(\theta) d \theta+\delta m_{t-1}\right]$. 


\subsection{The Domestic Household}

The domestic economy is comprised of identical infinitely lived households and the measure of these households is normalized to one. Households consume both traded and non-traded goods. They produce non-traded goods $Y_{\mathrm{N}}$, which they supply in a perfectly competitive market. They are endowed with a fixed amount of traded goods $\bar{\omega}$ every period and share in the profits of the traded sector $(1-\tau) \Pi_{\mathrm{T}, \mathrm{t}}$. They can also borrow $(B)$ and lend from the rest of the world at an interest rate $r_{t}$ (paid in terms of tradables). In this framework there is only firm level uncertainty and no aggregate uncertainty.

The representative household maximizes a life-time utility function of the form

$$
\max _{\substack{\left\{C_{\mathrm{T}, \mathrm{t}}\right\}_{t=0,}^{\infty},\left\{C_{\mathrm{N}, \mathrm{t}}\right\}_{t=0}^{\infty} \\\left\{Y_{\mathrm{N}, \mathrm{t}}\right\}_{t=0}^{\infty},\left\{B_{\mathrm{t}+1}\right\}_{t=0}^{\infty}}}\left[\sum_{t=0}^{\infty} \beta^{t}\left[\gamma \log C_{\mathrm{T}, \mathrm{t}}+(1-\gamma) \log C_{\mathrm{N}, \mathrm{t}}-\frac{\kappa}{2}\left(Y_{\mathrm{N}, \mathrm{t}}\right)^{2}\right]\right]
$$

subject to the following flow budget constraint.

$$
\left(1+r_{t}\right) B_{t}+C_{\mathrm{T}, \mathrm{t}}+p_{t} C_{\mathrm{N}, \mathrm{t}} \leq \bar{\omega}+p_{t} Y_{\mathrm{N}, \mathrm{t}}+(1-\tau) \Pi_{\mathrm{T}, \mathrm{t}}+B_{t+1}
$$

$C_{\mathrm{T}, \mathrm{t}}$ is the consumption of traded goods at time $t$ and $C_{\mathrm{N}, \mathrm{t}}$ is the consumption of non-traded

goods at time $t$. The term $-\frac{\kappa}{2}\left(Y_{\mathrm{N}, \mathrm{t}}\right)^{2}$ captures the disutility the individual experiences from producing non-traded output. $B_{t+1}$ represents the level of foreign debt in terms of traded goods held by domestic residents at the end of period $t . \Pi_{\mathrm{T}, \mathrm{t}}$ is the aggregate level of profits in the traded goods sector. The no-Ponzi constraint requires that

$$
\lim _{j \rightarrow \infty} \frac{B_{t+j}}{\Pi_{s=1}^{j}\left(1+r_{s}\right)} \leq 0
$$

The interest rate faced by households is assumed to be sensitive to the level of debt. We assume the interest rate rule employed by Mendoza and Uribe (2000), Schmitt-Grohe and Uribe (2001) wherein the interest rate is increasing in the country's level of net foreign debt. This assumption resolves the non-stationarity of debt problem that is typical in small open economy models where households have access to a risk free bond whose interest rate is determined exogenously abroad. See Schmitt-Grohe and Uribe (2001) for a detailed discussion of this issue. 


$$
1+r_{t}=1+r+f\left(\tilde{B}_{t}\right)
$$

where

$$
f\left(\tilde{B}_{t}\right)=\psi\left(e^{B_{t}-\bar{B}}-1\right)
$$

$\bar{B}$ is the steady state level of debt, $r$ is the risk-free world interest rate and $(1+r) \beta=1$.

Household optimization then requires that the following first-order conditions hold,

$$
C_{\mathrm{T}, \mathrm{t}+1}=\left[\left(1+r_{t}\right) \beta\right] C_{\mathrm{T}, \mathrm{t}}
$$

The optimal choice of $C_{\mathrm{N}, \mathrm{t}}$ implies

$$
C_{\mathrm{N}, \mathrm{t}}=\left(\frac{1-\gamma}{\gamma}\right)\left(\frac{1}{p_{t}}\right) C_{\mathrm{T}, \mathrm{t}}
$$

Equation (15) is the equilibrium condition for intra-temporal allocation between traded and non-traded goods. Finally, the optimal choice of $Y_{\mathrm{N}, \mathrm{t}}$ implies

$$
Y_{\mathrm{N}, \mathrm{t}}=\frac{\gamma}{\kappa} \frac{p_{t}}{C_{\mathrm{T}, \mathrm{t}}}
$$

The marginal cost of producing another unit of the non-traded good, $\kappa Y_{\mathrm{N}, \mathrm{t}}$, should equal the marginal benefit, $\frac{\gamma p_{t}}{C_{\mathrm{T}, \mathrm{t}}}$. Optimization also requires that the household exhaust its intertemporal budget constraint looking forward from every date $t$.

The real exchange rate $e$ is defined as the ratio of the home consumption-based price index $(P)^{6}$ to the rest-of-the-world price index $\left(P^{*}\right), e_{t}=\frac{P_{t}}{P_{t}^{*}}=\left(\frac{p_{t}}{p_{t}^{*}}\right)^{1-\gamma}$. In a small open economy $p_{t}^{*}$ is taken as given at every date $t$. The behavior of the real exchange rate then mimics the behavior of the home price of non-traded goods in terms of traded goods $p_{t}$.

\footnotetext{
${ }^{6}$ It can be shown that $P_{t}=\frac{p_{t}^{1-\gamma}}{\gamma^{\gamma}(1-\gamma)^{1-\gamma}}$ and $P_{t}^{*}=\frac{\left(p_{t}^{*}\right)^{1-\gamma}}{\gamma^{\gamma}(1-\gamma)^{1-\gamma}}$. (where we have assumed that preferences are the same in both countries). We have imposed the condition that there is purchasing power parity in tradables across countries.
} 


\subsection{Aggregation and Market Clearing Conditions}

Aggregate demand for the non-traded good from the traded goods sector is

$$
X_{\mathrm{N}, \mathrm{t}}=\int_{\theta_{L}}^{\theta_{H}} m_{t}(\theta) x_{\mathrm{N}, t} d \theta
$$

Aggregate level of output and profits in the traded sector is given by equations (18) and (19) respectively.

$$
\begin{gathered}
Y_{\mathrm{T}, \mathrm{t}}=\int_{\theta_{L}}^{\theta_{H}} y_{t}(\theta) m_{t}(\theta) d \theta \\
\Pi_{\mathrm{T}, \mathrm{t}}=Y_{\mathrm{T}, \mathrm{t}}-p_{t} X_{\mathrm{N}, \mathrm{t}}
\end{gathered}
$$

The goods-market clearing condition for non-traded goods is

$$
Y_{\mathrm{N}, \mathrm{t}}=C_{\mathrm{N}, \mathrm{t}}+X_{\mathrm{N}, \mathrm{t}}
$$

The current account is then ${ }^{7}$

$$
-B_{t+1}+B_{t}=\bar{\omega}+(1-\tau) Y_{\mathrm{T}, \mathrm{t}}+\tau p_{t} X_{\mathrm{N}, \mathrm{t}}-C_{\mathrm{T}, \mathrm{t}}+r_{t} B_{t}
$$

Definition 1 A search equilibrium is a sequence of the household's decisions $\left\{C_{\mathrm{T}, t}, C_{\mathrm{N}, t}, Y_{\mathrm{N}, t}, B_{t+1}\right\}$, foreign investors decisions that determine $\left\{\hat{\theta}_{t}\right\}$, real exchange rate $\left\{p_{t}\right\}$, the measure of searching investors $\left\{\eta_{t}\right\}$, the distribution of active projects $\left\{m_{t}(\theta)\right\}$ and traded sector output $\left\{Y_{\mathrm{T}, t}\right\}$ such that conditions (10-16), (3-8), and (17-21) hold, given initial conditions $\left\{B_{0}, \eta_{0},\left\{m_{-1}(\theta)\right\}\right\}$ and exogenous state $\left\{z_{t}, \phi_{t}, G(\theta)\right\}$

\section{Parameter Values}

In this section we describe the parameter values used to calibrate the model. A period in the model is equated to a quarter. The parameter values are taken from existing literature and average values for certain Latin American economies where available. Some fairly standard parameters are $\gamma$, the intratemporal elasticity of substitution between traded and non-traded goods in the consumption bundle. We set this at 0.5 as in Rebelo-Vegh (1995). The discount rate $\beta$ is set at 0.99 which corresponds to a quarterly world interest rate $r$ of

\footnotetext{
${ }^{7}$ We assume profits earned by foreign agents are repatriated to the foreign investors home country.
} 
$1.01 \%$. For $\psi$, the coefficient on the interest rate premium, we use the value of 0.000742 , which is the value used by Schmitt-Grohe and Uribe (2001) and implies that the interest rate faced by consumers is very close to the risk-free rate. Accordingly, consumption of traded goods adjusts very quickly to its long-run value. This property is useful for our analysis as we can focus on the transition dynamics that arise from search and evolution of projects.

To determine the choice of $\kappa$, the disutility parameter in the utility function from production of non-traded goods, we perform the following analysis as in Obstfeld-Rogoff (1996). It can be shown that the disutility term in the utility function is equivalent to the case where the production function in the non-traded sector is $y=A l^{\alpha_{\mathrm{T}}}$ and the disutility of supplying labor in the utility function is $-a l$ with $\alpha_{\mathrm{T}}$ set equal to 0.5. An $\alpha_{\mathrm{T}}$ of 0.5 is a reasonable measure of the share of labor in the non-traded sector. It is an average of the value used by Mendoza (2001) of 0.364 and the value used by Rebelo-Vegh (1995) of 0.63. Given this value for $\alpha_{\mathrm{T}}$ and normalizing $a$ and $A$ to 1 we have a value for $\kappa$ of 2 .

The parameters that are more specific to this model are $\delta$, the steady state project destruction rate and $G(\theta)$, the exante distributon of the pool of projects. We use evidence from firm level data to calibrate these parameters. In the absence of well known studies for emerging markets we rely on the analysis of Dunne, Roberts and Samuelson(1988) who examine the pattern of firm entry and exit in the U.S. 4 digit manufacturing industries (the relevant group for tradables sector) over the period 1963-1982 using data from census years. They define entry (exit) rates for industry $i$ between census years $t-1$ and $t$ as the ratio of the number of firms that enter (exit) industry $i$ between census year $t-1$ and $t$ to total number of firms in industry $i$ in census year $t-1$. Entry and exit rates are calculated to average close to 0.5 for the 5 year interval across census periods. The rates for U.S. firms are found to be fairly close to the numbers for the Canadian manufacturing sector as surveyed in Baldwin, Gorecki (1991) during the period 1970-82. In our model, the measure of entry and exit rate that corresponds precisely to the definition used in Dunne, Roberts, Samuelson(1988) is what we call the creation rate $C R_{t}$ and destruction rate $D R_{t}$.

$$
C R_{t}=\frac{\int_{\hat{\theta}_{t}}^{\theta^{*}} \eta_{t} d G(\theta)}{m_{t-1}}
$$




$$
D R_{t}=\frac{\left[(1-\delta) \int_{0}^{\hat{\theta}_{t}} m_{t-1}(\theta) d \theta+\delta m_{t-1}\right]}{m_{t-1}}
$$

In steady state, as the measure of active firms $m$ stays unchanged over time and $\int_{0}^{\hat{\theta}_{t}} m_{t-1}(\theta) d \theta$ is equal to zero the exit rate and entry rate are exactly equal to $\delta$. Accordingly, we set $\delta=0.025$.

The functional form we employ for the distribution of firm idiosyncratic productivity is a uniform distribution. We choose values for $\theta_{L}$ and $\theta_{H}$ so as to match evidence on dispersion of firm productivity in the manufacturing sector. Bartelsman and Doms (2000) perform the analysis for the U.S. They compute the ratio of average total factor productivity for plants in the ninth decile of the productivity distribution relative to the average in the second decile and find that the ratio varies between 2:1 in 1972 and 2-3/4 to 1 in 1987, with numbers as high as 4:1 for specific industries. Tybout (2000) surveys the evidence for manufacturing firms in developing countries, cautioning against the accuracy of the results given the quality of the data and methodology used. Evidence on dispersion relative to developed countries is mixed. Earlier evidence suggested that cross-firm variance in productivity level is high in developing countries while more recent evidence suggests otherwise. We try to match an intermediate dispersion number of 2.75. Normalizing $\theta_{L}$ to $1, \theta_{H}$ is set at 5 . This parameterization is clearly subject to the caveat that we are not matching all moments of the distribution of firm productivity and accordingly has its limitations.

$\bar{B}$ and $\omega$ are chosen such that the debt to GDP ratio is 0.35 , which corresponds to the average debt to gdp ratio for Mexico between 1970-1997 as computed by Mendoza(2001). The initial level of aggregate productivity in the traded sector $z$ is normalized to 1 . For $\alpha$ we use a value of 0.6 , which implies that the elasticity of response of non-traded goods used as inputs in the production of traded goods to a change in $p$ is 2.5. It is important to note that $\alpha$ does not correspond to the share of the cost of non-traded inputs in traded sector revenue. Infact it is necessarily lower than this ratio as given by equation (22) below. Given the choice of other parameters, this ratio is 0.0415 in our experiments.

$$
\frac{p X}{Y}=\frac{p\left(\frac{\alpha z}{p}\right)^{\frac{1}{1-\alpha}} m}{\int \theta m(\theta) d \theta+\int z x_{N}^{\alpha} m(\theta) d \theta}
$$


Lastly, we need to pick values for $\phi$, the per-period fixed cost of investing in the emerging economy and $\tau$, the fraction of profits in the traded sector that accrue to foreign investors. Unfortunately there is no clear way of selecting these values. A high $\phi$ and low $\tau$ reduces the incentive to invest in the emerging market. Our benchmark $\phi$ is set at 4 and $\tau$ at 0.8 . This implies that in steady state the fraction of searching investors in the potential pool of foreign investors is 0.57 . We will discuss the sensitivity of our results to alternate values of $\phi$ in Section 5. The benchmark parameter values are summarized in Table 1.

\section{The Economy in Steady State}

The equilibrium equations can be written in the form $\Gamma_{t+1}=g\left(\Gamma_{t}, z_{t}, \phi_{t}\right)$ where $\Gamma$ represents the vector of endogenous variables and the steady state is the solution to the equation $\Gamma=$ $g(\Gamma, z, \phi)$. There is no known closed form solution to these set of equations and accordingly the steady state values are obtained numerically as the solution to a system of non-linear equations, given the parameter values in Table 1.

Proposition 2 There exists a unique entry and exit cut-off $\hat{\theta}$, for a given $p$ and the cut-off is strictly increasing in $p$.

Proof. See Appendix A.1

Figure 1 depicts the steady state response of the relative price of non-traded goods to changes in aggregate traded sector productivity $z$, and changes in the fixed cost of investment $\phi$. A higher $z$ implies that a searching investor would be willing to accept a project with a lower idiosyncratic return. The asset value of the previously marginal project is now higher. The expected return from search is also higher, as the change in $z$ is permanent. The rise in the asset value of the marginal project is shown to be greater than the rise in the search option and this implies a decline in the idiosyncratic type of the marginal acceptable project. Consequently, more projects are accepted. It can be shown that $m=\frac{1-G(\hat{\theta})}{1-G(\hat{\theta})(1-\delta)}$, and is therefore a decreasing function of the cut-off $\hat{\theta}$. That is, the more selective the investment and the higher the likelihood of exiting the market, the lower the measure of active projects 
in the economy. With a larger measure of active projects the demand for domestic resources rises, pushing up the real exchange rate. A higher fixed cost of investment $\phi$ has a similar effect on $p$ as a lower $z$ and the argument follows as before. In the next section, we evaluate the transitional dynamics for an economy subject to unanticipated permanent changes in $z$ and $\phi$.

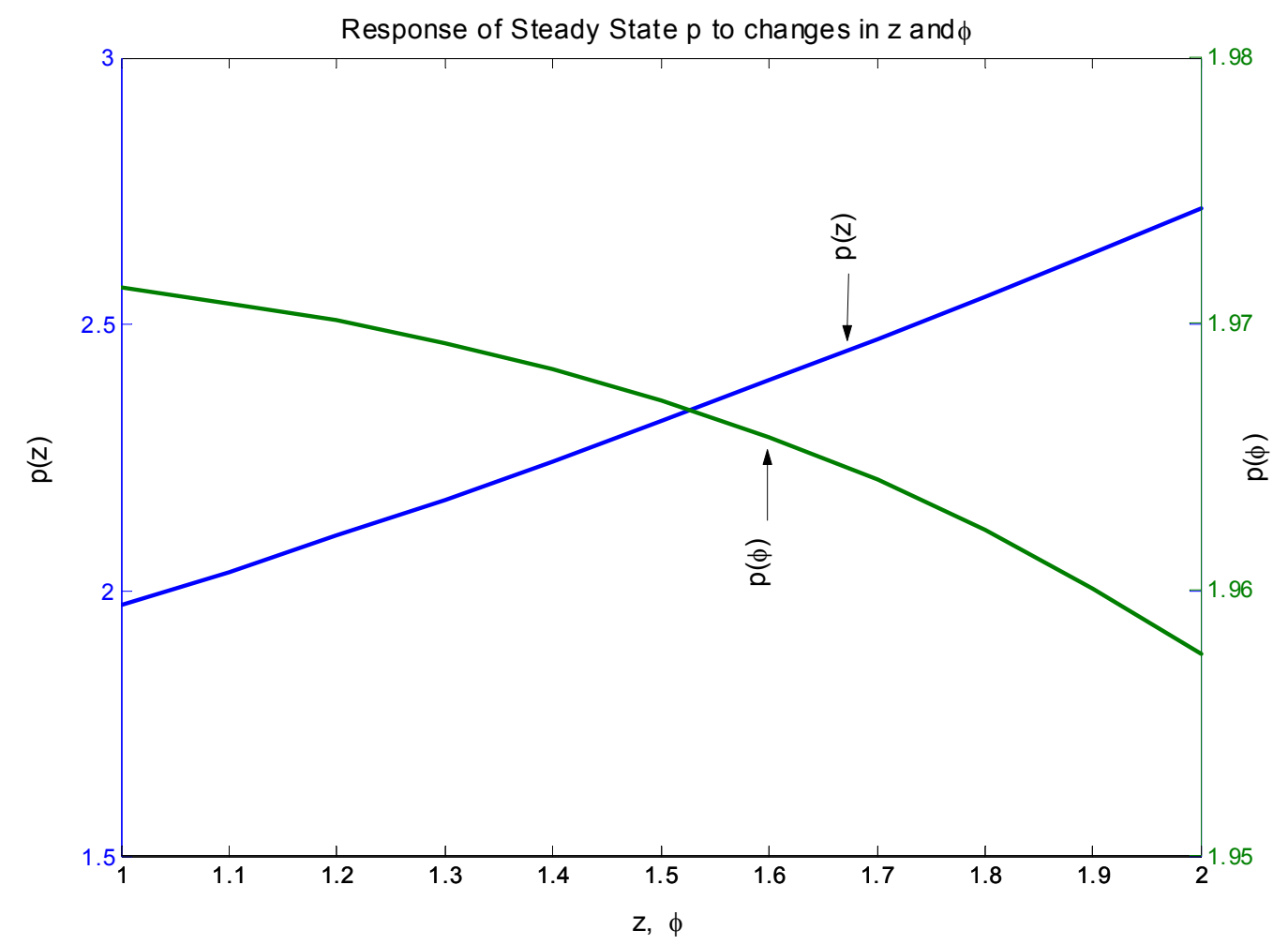

Figure 1

Figure 2 plots the steady state distribution of active projects for two values of the aggregate level of traded sector productivity, $z_{1}<z_{2}$. The intuition for the asymmetry in response to shocks to $z$ and $\phi$ (that will be demonstrated in the following section) can be seen here. When the economy moves from a steady state corresponding to $z_{1}$ to a higher level $z_{2}$, the cut-off level of idiosyncratic productivity falls. This induces more entry and reinvestment. Since the new cut-off lies to the left of the old, the mass of active projects in range between the cut-offs is necessarily zero. On the other hand, when the economy moves 
from $z_{2}$ to $z_{1}$ the cut-off is higher which lowers entry and reinvestment. Simultaneously, there is an immediate destruction of a strictly positive mass of projects that were worthy of investment in the state when aggregate traded sector productivity was high, but now are no longer viable. This additional destruction generates an asymmetry as the economy moves between good and bad states.
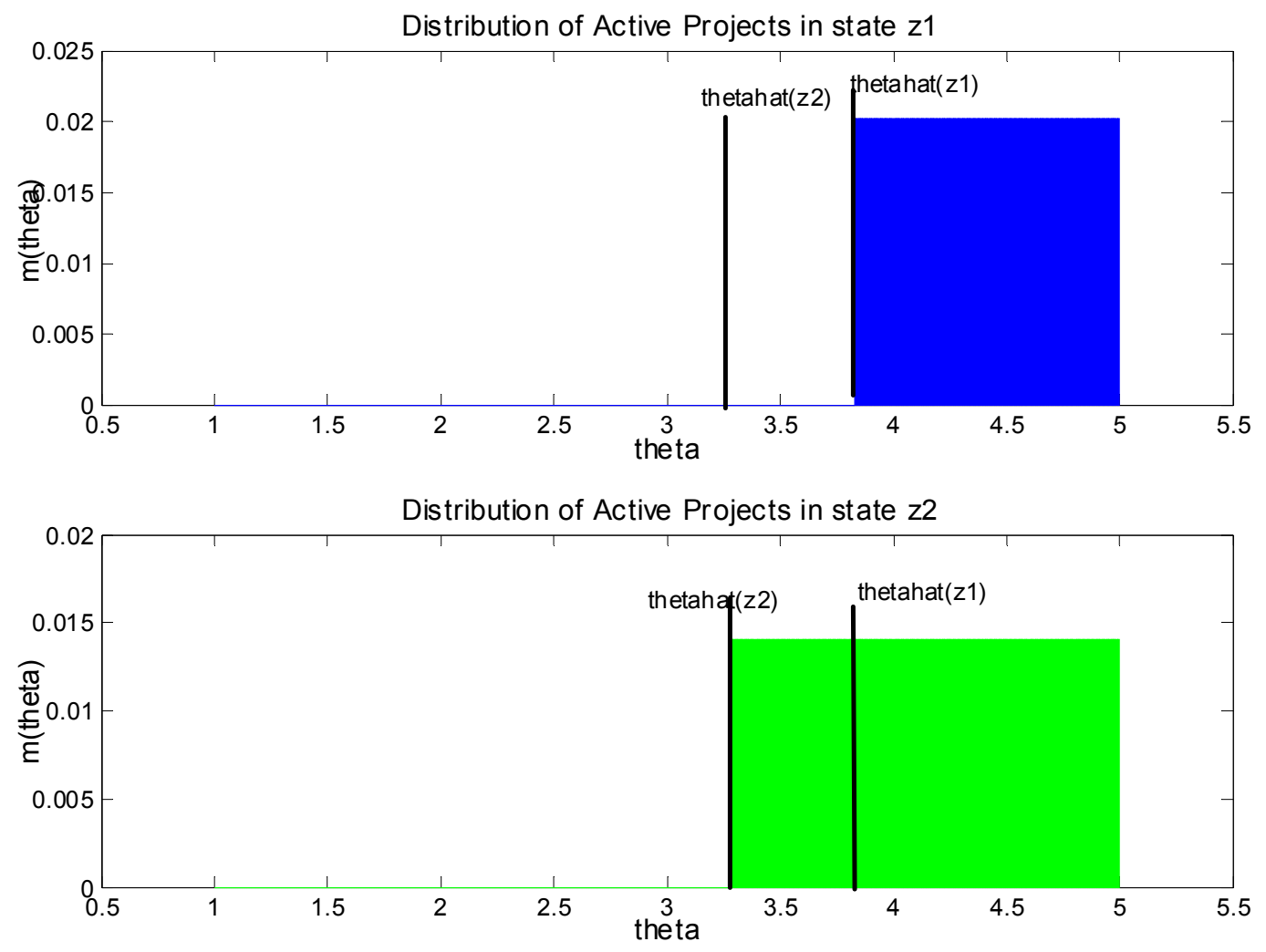

Figure 2

\section{Asymmetric Responses: Gradual Expansions and Sharp Contractions}

In this section, we examine the dynamic adjustment path of an economy that is characterized by the search friction in foreign investment flows. Several emerging market economies in the nineteen nineties that exhibited the boom-real exchange rate appreciation phenom- 
enon and subsequent sharp reversals experienced unprecedented levels of foreign investment inflows. The stimulus behind the increased flows to these economies has been attributed to a combination of improved domestic investment conditions and to worsening external factors such as lower returns on the U.S. stock market (Calvo-Leiderman-Reinhardt (1993)). The source of the reversal in the boom is a subject of greater debate. Aghion-Bacchetta-Banerjee (1999) for instance, describe an endogenous downturn along the lines of the Kiyotaki-Moore credit cycle mechanism. In Mendoza (2001), sources of the sudden stop are a negative shock to traded sector productivity, positive shock to world real interest rates and shocks to the tax rate. The experiment we consider is the response of the economy to permanent unanticipated changes in two variables: traded sector productivity $z$, and changes in the fixed cost of investment $\phi$. The main purpose of these experiments is to demonstrate the natural asymmetry in the adjustment path of the economy with the economy expanding gradually in response to positive shocks to $z$ and $\phi$ and contracting sharply in response to negative shocks.

As a measure of the shock to traded sector productivity, we use the standard deviation in traded sector productivity estimated for Mexico by Mendoza(2001) of 3.36\%. In our simulations we determine the response of the economy to a two standard deviation shock to traded sector productivity. More precisely, we consider the impulse response of an economy as it moves from $z^{l o}$ to $z^{h i}$ and vice-versa, where $z^{h i}$ is $6.5 \%$ higher than $z^{l o}$.

Since we are interested in the asymmetric response of the economy to positive and negative shocks, we cannot use linearization methods to solve for the dynamic response of the economy. Accordingly, we employ non-linear methods to obtain the solution which takes the form of a shooting algorithm. This is described in Appendix 2. The endogenous state space includes the entire distribution of active projects $m_{t-1}(\theta)$, the measure of searching investors $\eta_{t}$, and level of household debt $B_{t}$.

The solid lines in Figure 3 plot the impulse responses of the economy as it moves permanently from $z^{l o}$ to $z^{h i}$. The increase in $z$ makes investment in the projects more attractive to the foreign investor. The cut-off $\hat{\theta}$ declines on impact and more projects are accepted by investors who would previously have preferred to continue searching. All 
adjustment does not take place instantaneously because of the search friction. Investors will match slowly over time and we observe strictly positive net project creation along the transition path. Specifically, net project creation rises and declines along the transition path. This adjustment path is similar to the prediction one would obtain with quadratic adjustment costs. The asymmetry of the adjustment process is what distinguished the two frictions.

As more projects get activated, the demand for non-traded inputs in the expanding traded sector rise. This raises output and profits in the non-traded sector and the higher income to households from the traded sector causes consumption to rise. In a small open economy, with a perfectly elastic supply of traded goods, the increased demand for nontraded goods will result in an increase in the relative price of non-traded goods. The real exchange rate therefore appreciates. The gradualness of the expansion follows from the behavior of the measure of active projects, which monotonically increases over time owing to the search friction. Accordingly, the relative price of non-traded goods, $p$ and the $R E R$ appreciates on impact and continues to appreciate till it reaches its higher steady state value. Gross domestic product, $\bar{\omega}+p_{t} Y_{\mathrm{N}, \mathrm{t}}+\Pi_{\mathrm{T}, \mathrm{t}}$ and traded sector output similarly undershoot their long-run values. The consumption of traded goods $C_{\mathrm{T}}$, adjusts almost instantaneously to its long-run value, since the interest rate premium parameter is set at very close to zero. Since incomes of households are rising over time and consumers wish to smooth consumption they borrow from the rest of the world, resulting in current account deficits. Aggregate consumption in terms of traded goods also increases. $C_{\mathrm{T}}^{\gamma} C_{\mathrm{NT}}^{1-\gamma}$ rises on impact and declines along the transition path to a higher steady state level ${ }^{8}$.

Next, we consider the response of the economy as it moves from $z^{h i}$ to $z^{l o}$. The solid lines in Figure 4 plots the impulse responses. When the economy adjusts from $z^{\text {hi }}$ to $z^{l o}$ the cut-off increases on impact as the idiosyncratic return of the project required to ensure an adequate return to the investor is now higher. Projects that would have previously been accepted by searching investors are now rejected. Project creation therefore declines.

\footnotetext{
${ }^{8}$ In the data, consumption gradually increases over time as opposed to overshooting. Uribe (2002) explores the role of habit formation in preferences in generating this trend.
} 
Simultaneously, there exists a range of projects, between the previous cut-off and the new cut-off that were previously considered worthy of reinvestment but now get shut-down. As discussed in Section 4, the corresponding adjustment does not exist when the economy moves from $z^{l o}$ to $z^{h i}$. It is this asymmetry in the destruction rate that generates the asymmetry in the behavior of adjustment of the economy ${ }^{9}$.

As depicted in Figure 4, the measure of active projects declines sharply at the moment of the shock and overshoots its long-run lower steady state level. Consequently, non-traded sector prices, real exchange rate, gross domestic product and traded sector output is also to overshoot their downward adjustment. Table 2 (Case 1) compares the impact effect and long-run effect of an economy as it moves between $z^{l o}$ and $z^{h i}$. For the same set of parameter values, as the economy moves from $z^{l o}$ to $z^{h i} G D P$ increases on impact by $1.69 \%$ and is higher by $5.15 \%$ in the long-run. On the other hand, as the economy moves from $z^{h i}$ to $z^{l o}$ GDP declines on impact by $7.17 \%$ before recovering to a level that is $4.9 \%$ below the pre-shock steady state in the long-run. Similarly, traded sector output, in response to the expansionary shock raises on impact by $0.71 \%$ while declining on impact by $7.53 \%$, the $R E R$ appreciates on impact by $3 \%$ and depreciates on impact by $3.16 \%$. The measure of active projects similarly adjusts asymmetrically with monotonic expansions rising from $0.22 \%$ to $4.54 \%$ and non-monotonic contractions associated with a sharp decline on impact by $7.17 \%$ as compared to a long-run deviation of $4.34 \%$. Since project contraction is associated with exit of foreign investors from the project in this model, the sharp contraction implies sharp reversals in participation rates of foreign investors in the emerging economy. The overshooting results in households borrowing to smooth consumption. The deviation in current account deficit (as a ratio of pre-shock GDP) is $0.006 \%$.

It should be clear that the adjustment paths differ from what we would have obtained had we used a quadratic adjustment cost investment model. The mechanism that generates this asymmetry is also very different from the 'occasionally binding credit constraint' mechanism described in the literature where asymmetries are infrequent events and its occurence

\footnotetext{
${ }^{9}$ Mortenson and Pissarides (1994) describe this asymmetry in the destruction rate as it arises in a model of job flows when workers and vacancies match via a matching technology to create jobs. One requires some degree of persistence in the idiosyncratic return to obtain asymmetry in the adjustment process.
} 
depends on the initial net foreign asset position of the economy. In the search framework, the asymmetry is always present (even when the shocks are partly anticipated and agents incorporate this in their decisions), however its magnitude varies with the extent to which $z^{h i}$ and $z^{l o}$ differ and the consequent divergence in $\hat{\theta}^{h i}$ and $\hat{\theta}^{l o}$.

The quantitative predictions of the model are reported in Figures 3 and 4 and in Table 2 and 3. The solid line in Figures 3 and 4 plot the response to a permanent unanticipated change in $z$ and the dashed line plots the response to permanent unanticipated changes in $z$ and in the fixed cost of investment $\phi$. In the benchmark case $\phi^{h i}$ is equal to 4 and $\phi^{l o}$ is set at 3.9. In the absence of precise estimates from emerging market economy data for certain parameters used in the model the quantitative predictions have to be examined with caution. Further, we only look at permanent shocks. Despite this, it is illustrative to note that the effects on $G D P, m, Y_{\mathrm{T}}, p, R E R, C$ can be quite large in this framework and comparable to numbers obtained from the data. When the shock to $z$ is combined with the $2.5 \%$ shock to $\phi$ the effects on all the variables reported in the table rise substantially. Table 1 suggests that the long-run effect on the real exchange rate of a move from $\left\{z^{l o}, \phi^{h i}\right\}$ to $\left\{z^{h i}, \phi^{l o}\right\}$ is $12.4 \%$, the effect on GDP is $29.8 \%$, on consumption is $13.6 \%$ and on traded sector output is $30.3 \%$. Similarly, the reversals in these economies is also far more dramatic as compared to Case 1 in Table 2. In the Sudden Stops literature, Calvo-Reinhart (1999) document an average real GDP contraction of $13.3 \%$ during the recent crisis episodes for the group of Argentina, Indonesia, Korea, Mexico and Thailand. Mendoza (2001) analyzes time series date for Mexico and his estimates are reported in Table 3 alongside the numbers we obtain for the impact effect of a move from $z^{h i}$ to $z^{l o}$. Further, we qualitatively match the observation about sudden stops that recessions have tended to be very short lived since our model generates expansions in GDP immediately following the first period of the $\operatorname{shock}^{10}$.

Table 4 illustrates the sensitivity of the quantitative effects obtained to initial parameter choices in $\phi$. The main point is that the magnitude of the effects are larger, the greater the impact on the adjustment hazard rate of the shock. A high initial value of $\phi$ will imply a high

\footnotetext{
${ }^{10}$ Comparing our estimates to Rebelo-Vegh (1995), a case can be made that incorporating the real effects of investors subject to information frictions can be important in quantitatively matching the extent of movements in macro aggregates observed in these economies.
} 
cut-off, a low adjustment hazard rate and a larger pool of searching investors. Changes in $z$ and $\phi$ will have a larger effect in this case, as opposed to the scenario where the adjustment hazard rates are already high and the measure of searching investors in steady state is low.

The presence of foreign investors generates benefits to the local economy in terms of increasing their income through project creation. If we compare the steady state welfare of an economy in which households can trade in the risk-free bond but there are no searching foreign investors, to the steady state welfare of the economy we describe in this paper, the welfare gains are very large ${ }^{11}$. Further, we can evaluate the welfare effects on the current economy of shocks to traded sector productivity. When the economy is initially in the bad state, $\left\{z^{l o}\right\}$, the effect of a switch to the good state $\left\{z^{h i}\right\}$ is for welfare to rise. The compensating variation in terms of per-period consumption for an economy in steady state with $\left\{z^{l o}\right\}$ is calculated to be $3.02 \%$. Similarly when the economy moves from the good state to the bad state, the welfare loss measured as the compensating variation for an economy in steady state with $\left\{z^{h i}\right\}$ is a $1.97 \%$ drop in per -period consumption. One can examine at this point if there is a role for policy in smoothing out the sharp reversals that we observe in this economy. As long as the search friction exists there will remain an asymmetry in the adjustment process. The asymmetry is however greater the larger the rise in the cutoff that follows when the economy is hit by the bad shock. Policies that can reduce the wedge between $\hat{\theta}^{h i}$ and $\hat{\theta}^{l o}$ can therefore reduce the extent of asymmetry in the process. For instance, if policy makers could commit to a policy of lowering the entry cost for investors $\phi$, or raising the proportion of profits that accrue to investors $\tau$, when $z$ is low, this would drive $\hat{\theta}^{l o}$ to be close to $\hat{\theta}^{h i}$ and smooth out reversals.

\footnotetext{
${ }^{11}$ The percentage increase in per period consumption required to generate the same level of welfare for an economy closed to foreign investors is $200 \%$ and $230 \%$ depending upon whether $\{z, \phi\}=\{1,4\}$ or $\{z, \phi\}=\{1.065,3.9\}$ respectively $(\bar{B}=0)$. These large differences depend on our assumption than the non-endowment production of traded goods requires foreign participation and is therefore quite high.
} 


\section{Conclusion}

This paper explores the role of information imperfections in investing in emerging markets on the propagation of shocks in these markets. We demonstrate that in the presence of a search friction in foreign investors entry decision into emerging markets there arises a natural asymmetry in the adjustment process of the economy to shocks. An increase in traded sector productivity raises $G D P$ on impact and it continues to grow to a higher long-run level. On the other hand, a decline in traded sector productivity causes GDP to contract in the short run by more than it does in the long-run. We examine the role of this friction both qualitatively and quantitatively in explaining the behaviour of real exchange rates, traded and non-traded sector output, consumption and GDP. The results suggest an important role for such frictions in entry and exit decisions of investors in explaining the recent boom and collapse episodes of emerging market economies in the nineteen nineties.

\section{Appendix}

\section{Appendix A.1: Proof for Proposition 2}

Proof. It follows from equation (3) and (4) that in steady state we can express the following

$$
E_{\theta}(V(\theta))=\left[(1+r) \phi+\beta E_{\theta}(V(\theta))\right] G(\hat{\theta})+\int_{\hat{\theta}}^{\theta^{*}}\left[\frac{\tau \pi(\theta)+\beta \delta E_{\theta}(V(\theta))}{1-\beta(1-\delta)}\right] d G(\theta)
$$

Using integration by parts, and since $\pi^{\prime}(\theta)=1$ and from equation (4), we obtain the following relation for $E_{\theta}(V(\theta))$

$$
E_{\theta}(V(\theta))=\left(\frac{1}{1-\beta}\right)\left[(1+r) \phi+\frac{\tau}{1-\beta(1-\delta)} \int_{\hat{\theta}}^{\theta^{*}}(1-G(\theta)) d \theta\right]
$$

From equation (A.1.1) we have a negatively sloped relation between $E_{\theta}(V(\theta))$ and $\hat{\theta}$. From equation (4) we obtain

$$
\frac{\tau}{(1-\beta(1-\delta))}\left[\hat{\theta}+\chi z^{\left(\frac{1}{1-\alpha}\right)} p^{\left(\frac{-\alpha}{1-\alpha}\right)}\right]=(1+r) \phi+\left[\frac{\beta(1-\delta)(1-\beta)}{(1-\beta(1-\delta))}\right] E_{\theta}(V(\theta))
$$


which determines a positively sloped relation between $E_{\theta}(V(\theta))$ and $\hat{\theta}$. The intersection of (A.1.1) and (A.1.2) is necessarily unique. A higher $p$ results in a rightward shift of equation (A.1.2) implying a higher equilibrium cut-off and lower $E_{\theta}(V(\theta))$.

\section{Appendix A. 2: Numerical Solution Algorithm}

The dynamics of the model are obtained using a shooting algorithm. The steps are as follows

(i) The economy is assumed to be in its initial steady state in period 0 and assumed to reach its new steady state in period $T$. The steady state values are obtained numerically as the solution to a system of non-linear equations, given the parameter values in Table 1.

(ii) Next, we guess a transition path for the relative price of non-traded goods, $\left\{p_{t}^{0}\right\}_{t=1, \ldots T-1}$ . Given the path for $p_{t}$, we can solve for the path of $\left\{\hat{\theta}_{t}\right\}$ and $\left\{\overrightarrow{V_{t}(\theta)}\right\}$, starting from period $(T-1)$ and solving backwards. The vector $\overrightarrow{V_{t}(\theta)}$ is determined over 5000 grid points and the function $V_{t}(\theta)$ is approximated using a spline. The equations used are the value function (3) and the equation for the equilibrium cut-off (4). The profit function is solely a function of $p$ and consequently, the entire sequence of cut-offs can be determined.

(iii) Give the path of $\left\{\hat{\theta}_{t}\right\}$ and the initial distribution of active projects $\left\{\overrightarrow{m_{0}(\theta)}\right\}$, we can determine the path of $\left\{\overrightarrow{m_{t}(\theta)}\right\}_{t=1 \ldots . . T-1}$ according to the following relation

$$
\begin{aligned}
m_{t}(\theta)= & (1-\delta)^{t} I\left(\theta>\max \left(\left\{\hat{\theta}_{0}, \ldots, \hat{\theta}_{t}\right\}\right) m_{0}(\theta)\right. \\
& +(1-\delta)^{t-1} I \cdot\left\{\theta \geq \max \left(\left\{\hat{\theta}_{1}, \ldots, \hat{\theta}_{t}\right\}\right\} \eta_{1} g(\theta)\right. \\
& +(1-\delta)^{t-2} I \cdot\left\{\theta \geq \max \left(\left\{\hat{\theta}_{2}, \ldots, \hat{\theta}_{t}\right\}\right\} \eta_{2} g(\theta)+\ldots .+\right. \\
& +(1-\delta) I \cdot\left\{\theta \geq \max \left\{\hat{\theta}_{t-1}, \hat{\theta}_{t}\right\}\right\} \eta_{t-1} g(\theta)+ \\
& +\eta_{t} I\left(\theta>\hat{\theta}_{t}\right) g(\theta)
\end{aligned}
$$

where $I($.$) is the indicator function that takes the value 1$ if the statement within brackets is true and $\eta_{t}$ is determined according to

$$
\eta_{t}+(1-\delta) m_{t-1}=1
$$


and the aggregate measure of active projects is

$$
\begin{aligned}
m_{t}= & \int_{\hat{\theta}_{t}}^{\infty} m_{t}(\theta) d \theta \\
= & (1-\delta)^{t} h\left(\max \left\{\hat{\theta}_{0}, \ldots, \hat{\theta}_{t}\right\}\right) \frac{\eta_{0}^{s}}{\delta}+ \\
& +(1-\delta)^{t-1} h\left(\max \left\{\hat{\theta}_{1}, \ldots, \hat{\theta}_{t}\right\}\right) \eta_{1}^{s}+ \\
& +(1-\delta)^{t-2} h\left(\max \left\{\hat{\theta}_{2}, \ldots, \hat{\theta}_{t}\right\}\right) \eta_{2}^{s}+\ldots+ \\
& +(1-\delta) h\left(\max \left\{\hat{\theta}_{t-1}, \hat{\theta}_{t}\right\}\right) \eta_{t-1}^{s}+h\left(\hat{\theta}_{t}\right) \eta_{t}^{s}
\end{aligned}
$$

where $h()=.1-G($.$) .$

(iv) Given the evolution of $\left\{\overrightarrow{m_{t}(\theta)}\right\},\left\{m_{t}\right\}$ and $\left\{\eta_{t}\right\}$ the equilibrium level of $\left\{X_{\mathrm{N}, t}\right\},\left\{Y_{\mathrm{T}, \mathrm{t}}\right\}$, $\left\{B_{t}\right\},\left\{r_{t}\right\},\left\{C_{\mathrm{T}, t}\right\}$ and $\left\{C_{\mathrm{N}, t}\right\}$ are determined from equations (17), (18), (21), (12), (13), (14) and (15).

(v) The level of $\left\{Y_{\mathrm{N}, \mathrm{t}}\right\}$ is determined as the residual from the goods market clearing condition $Y_{\mathrm{N}, \mathrm{t}}=C_{\mathrm{N}, \mathrm{t}}+X_{\mathrm{N}, \mathrm{t}}$.

(vi) The new sequence of relative non-traded goods prices, $\left\{p_{t}^{1}\right\}$ is then obtained from the output supply equation, (16). If $\left\{\left|p_{t}^{1}\right|-\left|p_{t}^{0}\right|\right\}>\varepsilon$, steps (ii)-(vi) are repeated using a weighted average of the new sequence of prices $\left\{p_{t}^{1}\right\}$ and the previous sequence of prices $\left\{p_{t}^{0}\right\}$. This process is repeated as long as $\left\{\left|p_{t}^{i+1}\right|-\left|p_{t}^{i}\right|\right\}>\varepsilon$ (where $i$ indexes the number of the iteration). Also, we check to make sure that the economy has indeed converged to its new steady state. If not, we pick a new $T$ and repeat the steps starting from (ii).

\section{References}

[1] Aghion, Philippe, Philippe Bacchetta and Abhijit Banerjee, ' Capital Markets and the Instability of Open Economies, ' 1999, CEPR DP 2083.

[2] Arellano, Cristina and Enrique G. Mendoza, 'Credit Frictions and Sudden Stops in Small Open Economies: An Equilibrium Business Cycle Framework for Emerging Markets Crises', 2002, NBER Working Paper 8880.

[3] Baldwin, John R., and Paul K. Gorecki, 'Firm Entry and Exit in the Canadian Manufacturing Sector, 1970-1982', 1991, Canadian Journal of Economics 24(2), 300-323. 
[4] Bartelsman, Eric J., and Mark Doms, 'Understanding Productivity: Lessons from Longitudinal Microdata', 2000, Journal of Economic Literature, 38(3), 569-594.

[5] Caballero, Richard J, 'Aggregate Investment', 1997, NBER WP 6264.

[6] Caballero, Richard J and Eduardo M.R.A Engel, 'Non-Linear Aggregate Investment Dynamics: Theory and Evidence', 1998, NBER Working Paper 6420.

[7] Calvo, Guillermo A., Leonardo Leiderman and Carmen M. Reinhart, 'Inflows of Capital to Developing Countries in the 1990's: Causes and Effects', 1996, Journal of Economic Perspectives 10, 123-139.

[8] Calvo, Guillermo A., Leonardo Leiderman and Carmen M. Reinhart, 'Capital Inflows and Real Exchange Rate Appreciation in Latin America: The Role of External Factors', 1993, IMF Staff Papers 40(1),108-51.

[9] Calvo, Guillermo A. and Carmen M. Reinhart, 'When Capital Inflows come to a Sudden Stop: Consequences and Policy Options,' 1999, mimeo, Center for International Economics, Department of Economics, University of Maryland.

[10] Calvo, Guillermo A and C.A. Vegh (1993), 'Exchange Rate based Stabilization under imperfect credibility', Open Economy Macroeconomics, H. Frisch and A. Worgotter (eds.). London: MacMillan, 3-28.

[11] Calvo, Guillermo and Enrique G. Mendoza (2000), 'Capital-Markets Crises and Economic Collapse in Emerging Markets: An Informational-Frictions Approach, ' American Economic Review: Papers and Proceedings 90(2).

[12] Dunne, Timothy, Mark J. Roberts Larry and Samuelson, 'Patterns of Firm Entry and Exit in U.S. Manufacturing Industries', 1988, Rand Journal of Economics 19, 495-515.

[13] Ghosh, S and H. Wolf, 'The Geography of Capital Flows', 1999, in S. Edwards, ed., Capital Inflows to Emerging Markets, University of Chicago Press.

[14] Glick, Reuven edited 'Managing Capital Flows and Exchange Rates: Perspectives from the Pacific Basin', 1998, Cambridge University Press.

[15] Gopinath, Gita and Wojciech Olszewski, 'Investment Inflows into Emerging Markets: A Search Theroretic Approach', 1999, mimeo. 
[16] Mendoza, Enrique G, 'Credit, Prices and Crashes: Business Cycles with a Sudden Stop' (2001), NBER Working Paper 8338.

[17] Mendoza, Enrique G and Martin Uribe, 'Devaluation Risk and the Business-Cycle Implications of Exchange-Rate Management' (2000), Carnegie-Rochester Conference Series on Public Policy 53, 239-96.

[18] Mortenson, Dale. T., and Christopher A. Pissarides, 'Job Creation and Job Destruction in the Theory of Unemployment', 1994, Review of Economic Studies 61, 397-415.

[19] Obstfeld, Maurice and Kenneth S. Rogoff, 'Foundations of International Macroeconomics', 1996, The MIT Press, Cambridge, Masachussettes.

[20] Portes, Richard and Helene Rey, ' The Determinants of Cross-Border Equity Flows: The Geography of Information', 2000, mimeo.

[21] Rebelo, Sergio and Carlos Vegh, ' Real Effects of Exchange-Rate based Stabilizations: An Analysis of Competing Theories, ' 1995, NBER Macroeconomics Annual, 125-174.

[22] Schneider, Martin and Aaron Tornell, 'Balance Sheet Effects, Bailout Guarantees and Financial Crisis', 2000, NBER Working Paper 8060.

[23] Schmitt-Grohe, Stephanie and Martin Uribe, 'Closing Small Open Economy Models', 2001, Journal of International Economics, forthcoming.

[24] Tybout, James R., 'Manufacturing Firms in Developing Countries: How Well Do they Do, and Why?', 2000, Journal of Economic Literature 38, 11-44.

[25] Uribe, Martin, 'The price-consumption puzzle of currency pegs', 2002, Journal of Monetary Economics 49. 


\section{Table 1: Benchmark Parameter Values}

\begin{tabular}{|c|c|c|}
\hline Time preference rate & $\beta$ & 0.99 \\
\hline World risk-free interest rate & $\mathrm{r}$ & 0.01 \\
\hline $\begin{array}{l}\text { Fraction of spending by consumers } \\
\text { on non-traded goods }\end{array}$ & $\gamma$ & 0.5 \\
\hline $\begin{array}{l}\text { Disutility from production in } \\
\text { preferences }\end{array}$ & $\kappa$ & 2 \\
\hline $\begin{array}{l}\text { Elasticity of demand for non-traded } \\
\text { goods in traded sector }\left(\frac{1}{1-\alpha}\right)\end{array}$ & $\alpha$ & 0.6 \\
\hline Steady-state debt & $\mathrm{B}$ & 1.0038 \\
\hline Endowment of traded goods & $\omega$ & 0.001 \\
\hline Coefficient on interest rate premium & $\psi$ & 0.000742 \\
\hline Exit rate of firms in traded sector & $\delta$ & 0.025 \\
\hline$\theta_{L}$ of uniform distribution & $\theta_{L}$ & 1 \\
\hline$\theta_{H}$ of uniform distribution & $\theta_{H}$ & 5 \\
\hline $\begin{array}{l}\text { Share of profits accruing to foreign } \\
\text { investors }\end{array}$ & $\tau$ & 0.8 \\
\hline $\begin{array}{l}\text { Per-period fixed cost of investment } \\
\text { to foreign investor }\end{array}$ & $\phi$ & 4 \\
\hline Aggregate traded sector productivity & $\mathrm{z}$ & 1 \\
\hline
\end{tabular}


Table 2: Impact Effect and Long-Run Effect of permanent shocks to traded sector productivity (z) and fixed cost to foreign investor ( $\phi)$ (percentage changes)

\begin{tabular}{|c|c|c|c|c|}
\hline \multirow[t]{2}{*}{ Case 1: } & $\multicolumn{2}{|c|}{z^{l o}, \phi^{h i}}=\{1,4\} \rightarrow\left\{z^{h i}, \phi^{h i}\right\}=\{1.065,4\}$ & $\multicolumn{2}{|c|}{z^{h i}, \phi^{h i}}=\{1.065,4\} \rightarrow\left\{z^{l o}, \phi^{h i}\right\}=\{1,4\}$ \\
\hline & Impact Effect & Long Run Effect & Impact Effect & Long Run Effect \\
\hline$G D P$ & 1.69 & 5.15 & -7.17 & -4.90 \\
\hline$R E R$ & 3.00 & 3.15 & -3.16 & -3.06 \\
\hline$M$ & 0.22 & 4.54 & -7.17 & -4.34 \\
\hline C & 2.9 & 2.75 & -2.57 & -2.67 \\
\hline$Y_{T}$ & 0.71 & 4.96 & -7.53 & -4.73 \\
\hline \multirow[t]{2}{*}{ Case 2: } & $\multicolumn{2}{|c|}{z^{l o}, \phi^{h i}}=\{1,4\} \rightarrow\left\{z^{h i}, \phi^{l o}\right\}=\{1.065,3.9\}$ & $\multicolumn{2}{|c|}{z^{h i}, \phi^{l o}}=\{1.065,3.9\} \rightarrow\left\{z^{l o}, \phi^{h i}\right\}=\{1,4\}$ \\
\hline & Impact Effect & Long Run Effect & Impact Effect & Long Run Effect \\
\hline GDP & 5.84 & 29.8 & -36.49 & -22.97 \\
\hline$R E R$ & 11.58 & 12.4 & -11.72 & -11.03 \\
\hline$M$ & 1.95 & 32.6 & -40.96 & -24.6 \\
\hline$C$ & 14.49 & 13.6 & -11.34 & -12.03 \\
\hline$Y_{T}$ & 0.81 & 30.3 & -39.82 & -23.25 \\
\hline
\end{tabular}


Table 3: Sharp Reversals

( percentage changes)

\begin{tabular}{|c|c|c|c|c|}
\hline & \multicolumn{2}{|c|}{ Model Estimates* } & \multicolumn{2}{|c|}{ Estimates from Data** } \\
\hline$\% \Delta G D P$ & \multicolumn{2}{|c|}{-7.17} & \multicolumn{2}{|c|}{-7.93} \\
\hline$\% p$ & \multicolumn{2}{|c|}{-6.22} & \multicolumn{2}{|c|}{-24.4} \\
\hline$\% \Delta C$ & \multicolumn{2}{|c|}{-2.57} & \multicolumn{2}{|c|}{-8.56} \\
\hline$\% \Delta Y T$ & \multicolumn{2}{|c|}{-7.53} & \multicolumn{2}{|c|}{-10.14} \\
\hline$\% \Delta Y N$ & \multicolumn{2}{|c|}{-0.59} & \multicolumn{2}{|c|}{-6.0} \\
\hline \multicolumn{5}{|c|}{$\begin{array}{l}\text { * Impact Effect of a } 6 \% \text { decline in traded sector productivity. } \\
\text { ** Refers to the estimates reported in Mendoza (2001) for Mexico. }\end{array}$} \\
\hline \multicolumn{5}{|c|}{$\begin{array}{c}\text { Table 4: Sensitivity of Long-Run Effects to initial adjustment hazard rate } \\
\text { (Variations in } \phi)\end{array}$} \\
\hline & $\phi=4.0$ & $\phi=3.9$ & $\phi=3.75$ & $\phi=3.5$ \\
\hline$\% \Delta$ Adjustment Hazard & 75.44 & 44.01 & 22.91 & 11.37 \\
\hline$\% \Delta G D P$ & 29.8 & 14.74 & 6.46 & 2.79 \\
\hline$\% \triangle R E R$ & 12.4 & 6.91 & 3.58 & 1.99 \\
\hline$\% \Delta m$ & 32.6 & 15.68 & 6.59 & 2.57 \\
\hline$\% \Delta C$ & 13.6 & 7.13 & 3.30 & 1.54 \\
\hline$\% \Delta Y T$ & 30.3 & 14.79 & 6.35 & 2.62 \\
\hline
\end{tabular}

Values in the table correspond to long-run effects of a permanent $6.5 \%$ increase in traded sector productivity and $2.5 \%$ decline in the fixed cost to investors, where the initial steady state parameters correspond to the benchmark parameters with the exception of $\phi$ which we vary as in the first row above. 


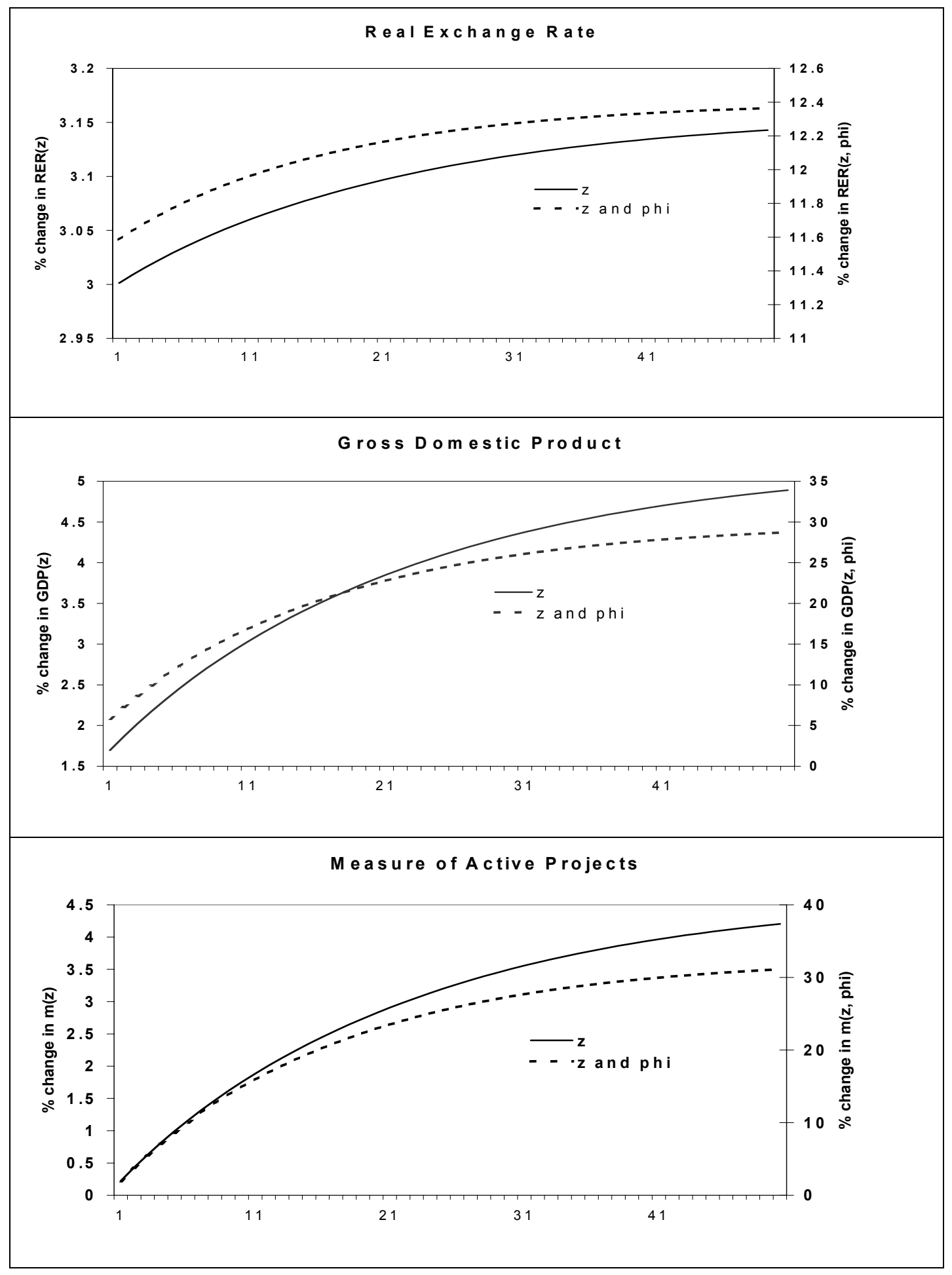

Figure 3: Solid line represents the impulse response to increase in traded sector productivity when the economy moves form $\left\{z^{\text {lo }}\right\}=\{1\}$ to $\left\{z^{\text {hi }}\right\}=\{1.065\}$ (the relevant axis is the left $Y$ axis). The dashed line represents the impulse response to an increase in traded sector productivity and lower fixed cost for foreign investor: $\left\{z^{l o}, \phi^{h i}\right\}=\{1,4\}$ to $\left\{z^{h i}, \phi^{l o}\right\}=\{1.065,3.9\}$ (relevant axis is the right $Y$ axis). Values represent percentage deviation from the initial steady state. 


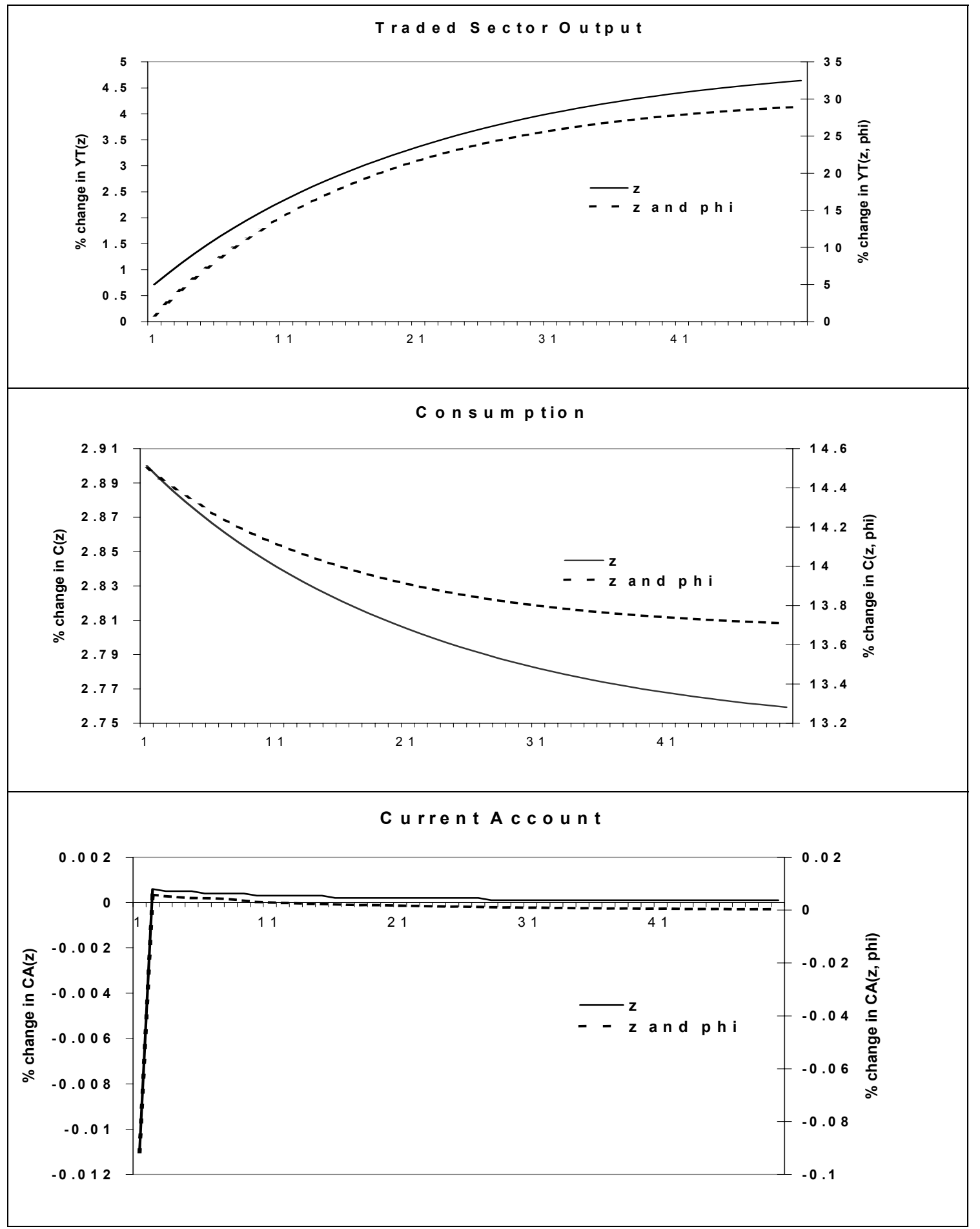

Figure 3(cont.) : Solid line represents the impulse response to increase in traded sector productivity when the economy moves form $\left\{z^{l o}\right\}=\{1\}$ to $\left\{z^{\text {hi }}\right\}=\{1.065\}$ (the relevant axis is the left $Y$ axis). The dashed line represents the impulse response to an increase in traded sector productivity and lower fixed cost for foreign investor: $\left\{z^{l o}, \phi^{h i}\right\}=\{1,4\}$ to $\left\{z^{h i}, \phi^{l o}\right\}=\{1.065,3.9\}$ (relevant axis is the right $Y$ axis). Values represent percentage deviation from the initial steady state. 


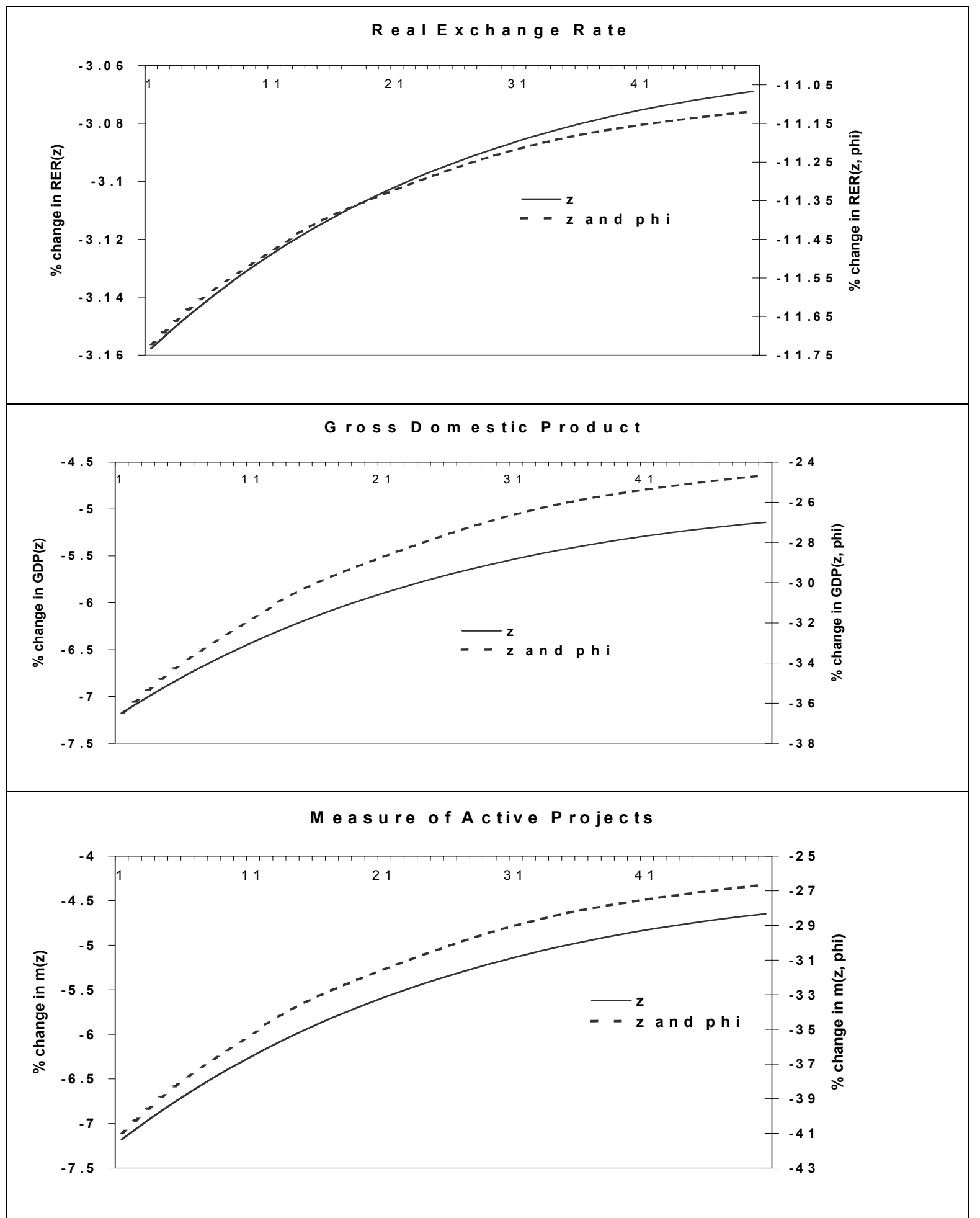

Figure 4: Solid line represents the impulse response to decrease in traded sector productivity when the economy moves form $\left\{z^{\text {hi }}\right\}=\{1.065\}$ to $\left\{z^{l o}\right\}=\{1\}$ (the relevant axis is the left $Y$ axis). The dashed line represents the impulse response to a decrease in traded sector productivity and higher fixed cost for foreign investor: $\left\{z^{h i}, \phi^{l o}\right\}=\{1.065,3.9\}$ to $\left\{z^{l o}\right.$, $\left.\phi^{h i}\right\}=\{1,4\}$ (relevant axis is the right Y axis). Values represent percentage deviation from the initial steady state. 


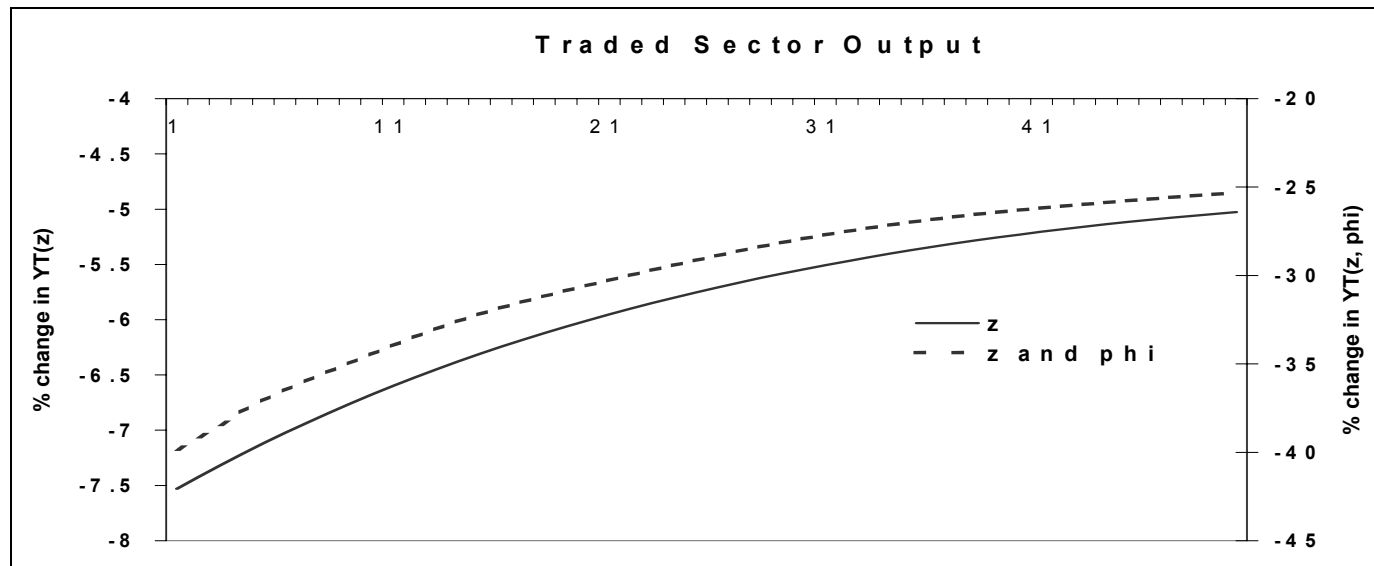

C o n s u m ption

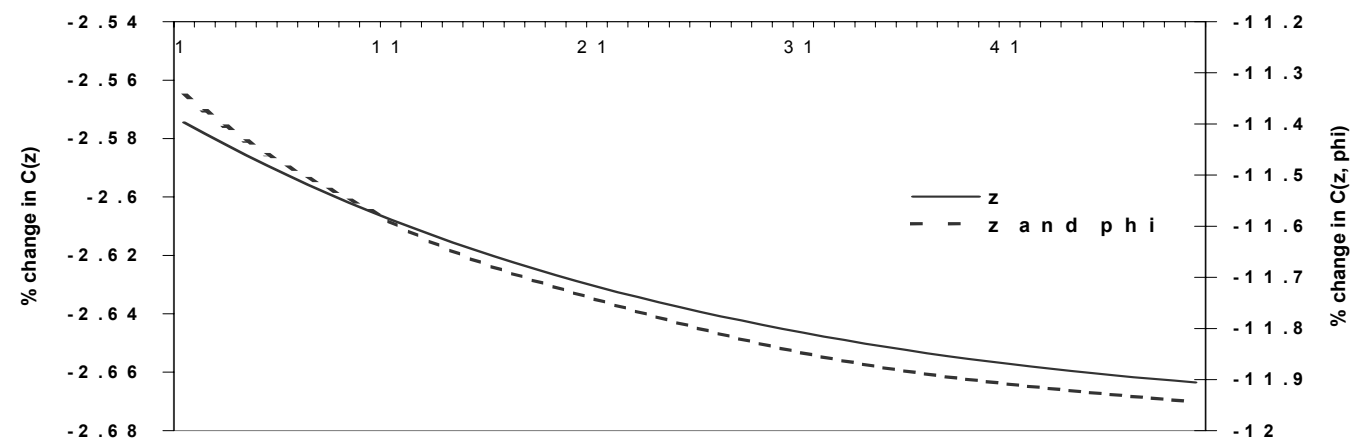

C u r r e n t A c o u n t

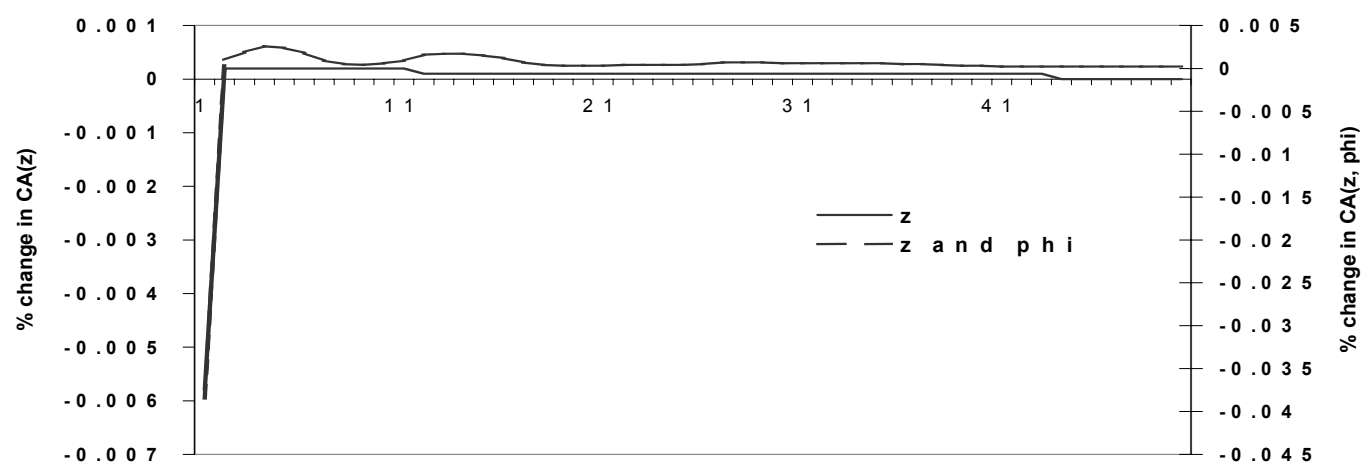

Figure 4(cont.): Solid line represents the impulse response to decrease in traded sector productivity when the economy moves form $\left\{z^{\text {hi }}\right\}=\{1.065\}$ to $\left\{z^{l o}\right\}=\{1\}$ (the relevant axis is the left $Y$ axis). The dashed line represents the impulse response to a decrease in traded sector productivity and higher fixed cost for foreign investor: $\left\{z^{h i}, \phi^{l o}\right\}=\{1.065,3.9\}$ to $\left\{z^{l o}, \phi^{h i}\right\}=\{1,4\}$ (relevant axis is the right Y axis). Values represent percentage deviation from the initial steady state. 